\title{
Getting Good at Small Talk: Student-Directed Learning of Social \\ Conversation Skills
}

\author{
Veerle Garrels*
}

*Corresponding author:

Veerle Garrels, Department of Special Needs Education, Faculty of Educational Science, University of Oslo, Norway

Postal address: Postboks 1140 Blindern, 0318 Oslo, Norway

Email: veerle.garrels@isp.uio.no

Telephone: \# 47976851 


\begin{abstract}
For students with autism spectrum disorders (ASD), learning social skills is an intricate but essential task to facilitate social inclusion and participation. Limited research is available on social skills interventions for adolescents with ASD and intellectual disabilities (ID). This article presents a case study that illustrates how the Self-Determined Learning Model of Instruction was used to improve self-chosen social conversation skills in a Norwegian 14-year old student with ASD and mild ID. This case study illustrates that, also for students with ASD and ID, giving them the opportunity to set personally relevant goals may improve their autonomous motivation, thereby increasing the likelihood of goal attainment.
\end{abstract}

\title{
Keywords
}

autism spectrum disorders, intellectual disability, social skills, goal setting, SDLMI

\section{Autism Spectrum Disorders and Social Skills Interventions}

Autism spectrum disorders (ASD) are characterized by significant impairment in social communication and social interaction (American Psychiatric Association 2013). ASD is a lifelong condition, and many persons with ASD struggle with social functioning throughout life (van Engeland and Buitelaar 2008). Impaired social skills can affect development in all areas, and these deficits may hamper interaction with peers, family, and others (Krasny et al. 2003). The social impairments are not explained by a lack of social interest, as many persons with ASD experience loneliness and isolation (Bauminger and Kasari 2000). Persons with ASD identify significantly more often social goals when given the chance to self-select goals compared to students with other disabilities, indicating an awareness of their social challenges (Kleinert et al. 
2014). When persons with ASD identify social goals for themselves, it is likely that they will have an autonomous motivation for these self-chosen goal, making goal attainment more within reach. Indeed, research has shown that students are more engaged and persistent in the learning process when working on goals of which they perceive a personal value (Carr, Moore, and Anderson 2014).

There is substantial empirical evidence supporting the effectiveness of a variety of social skills interventions for individuals with ASD. However, Reichow and Volkmar (2010) accentuate the paucity of interventions focusing on adolescents with ASD, as most of the research focuses on younger children. They also found that social skills interventions are scarce for adolescents with a double diagnosis of ASD and intellectual disability (ID). Another gap in the literature base is the limited research on student-directed interventions. In a review on single-case social skills interventions, Hutchins et al. (2017) found that the most commonly targeted behaviors were disruptive behaviors. These are typically teacher-identified rather than student-set intervention goals. Also more pro-active social skills programs tend to focus on teaching a preset package of social skills. While several of these programs may be effective, it can be questioned whether the student's voice is sufficiently heard in these interventions. For example, Krasny et al. (2003) emphasize the need to inform participants with ASD in social skills interventions why the selected goals are relevant for them, as this may facilitate learning. When students choose their own goals, personal relevance is more probable. Since many individuals with ASD are aware of their social difficulties, their insight and self-knowledge may be an important motivational factor. 


\section{The Self-Determined Learning Model of Instruction}

One model of engaging students in setting personally relevant goals for themselves, is the Self-Determined Learning Model of Instruction (SDLMI). This is a student-directed instructional model that promotes student involvement in the different phases of the learning process (Wehmeyer et al. 2000). The SDLMI is a versatile model of instruction, which can be used in different educational situations. In the SDLMI, the educator guides the student through the model's three phases, where each phase has four questions. In the first phase, the student identifies a desired goal. In the second phase, the student develops an action plan, and in the third phase, the student evaluates goal attainment. The SDLMI is conversation-based, and the questions within each phase help the student to identify what he wants to learn, solve problems, and evaluate what has been learned. While it is the educator who provides direction to the conversation by following the questions within each phase, the student is the primary agent for the choice of goals and actions. Each phase of the SDLMI provides educational support for teachers, and throughout the entire process, the teacher plays a central role as facilitator, student advocate and instructor (Wehmeyer et al. 2000).

Research indicates that the SDLMI can help students attain self-chosen goals (Shogren et al. 2012). A meta-analysis adds further evidence for the efficacy of the SDLMI as a way of promoting goal attainment for students with diverse disabilities (Lee, Wehmeyer, and Shogren 2015). While there is ample evidence for the effectiveness of the SDLMI in promoting goal attainment for students with other disabilities, few studies have focused on participants with ASD. In Lee et al.'s meta-analysis, only $4 \%$ of the participants had a diagnosis of ASD. A review that looked into 21 studies that used the SDLMI found that, out of 1054 participants, only 13 were diagnosed with ASD, i.e. $1.23 \%$ (Hagiware, Shogren, and Leko 2017). Wehmeyer et al. 
(2010) underscore this gap in the research base, and they emphasize that students with ASD also wish to be involved in decisions related to their life.

\section{Purpose of the study}

Given the paucity of research studies that investigate social skills interventions for adolescents with both ASD and ID, this study wishes to examine whether the SDLMI can be used for helping an adolescent with this double diagnosis to attain a self-chosen social goal. The SDLMI has been used mostly to help students gain academic and transitional goals, whereas its use for attaining social goals has been left largely unexplored. This study wishes to address this gap in the literature base.

\section{Method}

As this study moves into the little explored terrain of student-directed social skills interventions, an uncontrolled case study design was opted for. This kind of case study provides a weak basis for causal inferences and generalizations because of the absence of controls and rigorous procedures, but the design may be a useful source for new hypotheses and for developing new interventions (Kazdin 2011). Given the previously identified research gaps, the case study design may also help to inform and inspire other researchers and educators to involve students with ASD and ID in the planning and executing of social skills interventions.

\section{Participant}

Nora is a 14-year old eighth grader with ASD and mild ID (see note 1). She receives her education in a segregated special education classroom within her local school. A large part of her academic training occurs in one-on-one sessions with a special educator. Nora is a cheerful and 
talkative student when she is around adults, but she struggles socially with her peers. She often feels left out and bullied. She yearns for a closer friendship with the other girls in her class, but she worries that they do not have common interests. Nora expresses a clear desire to improve her social skills, so that she can feel more included.

\section{Measures}

- Observation checklist: Nora's progress was assessed by an observation checklist. Since Nora identified a goal about learning how to small-talk with peers during lunch, the researcher developed the observation checklist based on the benchmarks for starting conversations described by Kinney and Kinney (2003). The checklist included the following behaviors: i) saying peer's name, ii) making eye contact, iii) ask a question, iv) listen to response, v) give relevant response or ask new question, vi) stick to the theme when responding, vii) talk clearly, and viii) use normal voice volume. When Nora performs each of these behaviors during an observation, this results in 100 $\%$ correct performance at that given data point. Throughout the study, Nora was observed during lunch break three times per week. These regular observations allowed the researcher to monitor which of the target behaviors needed further practicing. Data were plotted in a progress chart for visual analysis.

- Interview schedule: Short interviews were conducted with Nora after each observation to assess her experiences. Nora indicated on a five-point Likert scale how she had experienced her small talk during lunch. Then she was asked to identify which peers she had interacted with, and which topics they had addressed. These brief interviews were also used actively to reinforce Nora's efforts, by giving specific praise about what she did well and where she had improved. 


\section{Ethics}

Written consent was obtained from Nora's parents and teacher. Nora was provided written information with visual support about the study, and she assented orally to participation. She was informed that she could withdraw from the study any time, and information was given about what she could say in case she no longer wished to participate. The study was approved by the Norwegian Centre for Research Data.

\section{Implementing the SDLMI}

\section{Phase 1: Choosing a Goal}

At the start of the study, the researcher and Nora have a conversation about what Nora enjoys doing at school and at home, and which possible goals she pictures for herself. For this purpose, the researcher discusses with Nora what it means to have a goal and examples of possible goals are given. While the researcher mentions goals within areas such as mathematics and cookery class, Nora seems mostly interested in social goals, such as tolerating being in a large group of people, doing small talk with the other girls during lunch, and asking a teacher for help when she encounters problems. Nora's focus on social goals may indicate an awareness of her social challenges; she is quite articulate when identifying her needs and desires, and she needs little scaffolding in this part of the process. The researcher contributes to the conversation mainly by asking follow-up questions, acknowledging Nora's experienced difficulties, giving her time to think, and paraphrasing what she says to make sure that she is understood correctly. The first conversation is rounded off by summing up Nora's possible goals, and by asking her to think about which goal she wants to work on first. 
During the second conversation, Nora identifies the goal about small talk with peers during lunch as her prioritized goal. After having identified her goal, the researcher helps Nora find answers to the other questions of the first phase of the SDLMI (figure 1). Here, Nora indicates that she knows how to respond when other students ask her a question, but that she finds it hard to initiate a conversation. When the researcher asks Nora to describe her usual behavior during lunch, she answers that she typically looks down at the table while eating, listening to what others say but not participating in the conversation herself. Thus, she feels that she needs to learn how she can start a conversation and how to keep it going.

After this second conversation, the researcher develops the observation checklist for charting Nora's progress towards her goal. An initial observation during lunch helps establish a baseline, and this confirms her socially inactive behavior. Nora's teacher also confirms this behavior as typical for Nora.

\section{Phase 2: Taking Action}

During the second phase of the SDLMI, an action plan is developed. While Nora initially often responds "I don't know" to the questions in this phase, paraphrasing what she says and asking further questions reveals that she usually does have some insight and ideas in what might help her socialize more during lunch (figure 2). Nora identifies the place where she is seated during lunch as a barrier to her interaction with the other girls, as she was seated in between her male peers for whom she stated to have no interest at all. This issue was easily resolved by changing places.

Nora also indicates that she needs to identify topics to talk about with the other girls, and she agrees on practicing this together with the researcher. While Nora identifies her needs by 
herself, she does rely on the expertise of the researcher to help her find useful learning strategies. This emphasizes that, while the SDLMI is a student-directed model of instruction, the educator continues to play a vital role as instructor and facilitator. With the help of the researcher, Nora chooses to practice social skills by means of "topic cards", and three times per week they practice social conversation skills together. For the topic cards, the researcher makes a stack of cards with different topics, such as weekend plans, lunch box contents, etc. The researcher and Nora take turns picking cards and ask and answer as many questions as possible for each topic. Whenever Nora does not know what to ask about a certain topic, the researcher gives her suggestions about how she can carry on. Nora also practices commenting and asking follow-up questions, and she gets feedback on whether her questions and comments are on or off topic. Some time is also spent explaining why people engage in small-talk, and how it serves an important social function. After each round of practice, the researcher asks Nora which of the topics she wants to talk about with her peers during lunch. Nora then gets to take the selected topic cards with her, and she keeps these in her pocket during lunch as a reminder.

The researcher further provides Nora with a card with a "five-point script for lunch talk" (figure 3). This script overlaps with the target behaviors on the observation checklist, so that Nora knows which behavior will lead to goal attainment. Before each observation, the researcher and Nora read through the script together to remind her which behaviors will lead to successful social interaction.

After each training session, the researcher observes Nora during lunch and tracks her actions on the observation checklist. Then follows a short interview with Nora, where she expresses her thoughts about that day's lunch conversation. The interviews reveal that she is 
satisfied with her efforts, and that, while she initially finds it scary to start small-talking, she gets more confident during the intervention weeks.

\section{Phase 3: Adjusting the Goal or Plan}

In the SDLMI's third phase, Nora and the researcher evaluate Nora's actions and whether she has reached her goal (figure 4). Nora is satisfied with the outcome and feels that she has achieved her goal. The progress chart (figure 5) shows that Nora achieved stable goal attainment, ranging from 87.5 to $100 \%$ correct performance. With this chart, it is visualized for Nora how her efforts with working on her plan helped her to achieve her goal. This may help her develop a stronger sense of personal empowerment and self-efficacy (Shogren, Wehmeyer and Palmer 2017).

Finally, the intervention is assessed by means of a short interview with Nora. Nora expresses that she enjoyed setting her own goals and evaluating her progress. She is interested in continuing using the SDLMI to set new goals, as she wants to decide more things by herself.

While there was no focus on generalization of the practiced skills to other situations, school staff did report that they had observed Nora engaging in small talk with her peers several times during cookery class, a behavior that she did not show prior to the intervention.

\section{Discussion}

This case study illustrates that it is possible for adolescents with both ASD and ID to set and attain self-chosen social goals. However, this may not be within reach for all students with this double diagnosis, and the severity of ASD and ID symptoms may limit students' ability to take part in an intervention as described in this study. Nonetheless, it is important to recognize 
that acquiring the necessary skills to set and attain goals is a learning process. Students who initially do not have all the required capacities, may get more skilled through positive experiences. Also, it is not necessary that students acquire all skills simultaneously. Instead, the educator may choose to expose students gradually to training of these different skills.

When implementing the SDLMI, some students may not have the life experience that enables them to answer all the questions in the model, and the language of the questions may not be understood by all students with disabilities (Wehmeyer et al. 2000). This makes it necessary for the educator to provide sufficient support throughout the conversations. Rephrasing the questions, providing visual support, or simply providing more time may be required. Students who need extra scaffolding to start with, may become more independent as they gain more experience.

In this case study, setting and attaining goals was the primary focus of investigation. In a larger context, goal setting skills form an important component element of self-determined behavior (Wehmeyer and Shogren 2017). Research indicates that students with ASD may experience lower levels of self-determination than for example students with learning disabilities (Seo et al. 2012), and therefore, specific interventions for this group of students may be required. Whilst the primary goal of this case study was to explore whether the SDLMI could be used to help students with ASD and ID to obtain self-chosen social goals, this article also invites researchers and practitioners to investigate further the effect of the SDLMI on self-determination outcomes for this target group.

\section{Limitations of the study}


This article describes an uncontrolled case study with one participant only, and inferences and generalizations that can be drawn from this study are limited. The purpose of the study has been to inspire educators and researchers to involve students with ASD and ID in social skills interventions. Further research with larger samples and more methodological rigor is needed to gain evidence for this type of intervention.

\section{Conclusion}

This article showed how the SDLMI can be used to help a student with ASD and ID to improve social conversation skills based on a self-chosen social goal. When asked, students with ASD will frequently identify social goals for themselves, and their awareness of social impairment may increase their motivation for social skills training. The SDLMI is a studentdirected instructional model that allows students to identify personally relevant goals and to develop action plans to achieve their goals. In this article, we have seen how the SDLMI was used to improve social conversation skills in a teenage girl with ASD and ID. Data indicate that the student in question improved her small-talk skills with peers, and that she maintained this enhanced performance throughout the intervention.

\section{Note}

1. This article describes an authentic situation. For anonymity, the student's name has been changed.

\section{References}

American Psychiatric Association. 2013. Diagnostic and statistical manual of mental disorders. $5^{\text {th }}$ edition. Washington D.C. 
Bauminger, N. and C. Kasari. 2000. "Loneliness and Friendship in High-Functioning Children with Autism." Child Development 71: 447-456. DOI: 10.1111/1467-8624.00156

Carr, M. E., D.W. Moore, and A. Anderson. 2014. “Goal Setting Interventions: Implications for Participants on the Autism Spectrum." Review Journal of Autism and Developmental Disorders 1: 225-241. DOI:10.1007/s40489-014-0022-9.

Hagiwara, M., K. Shogren, and M. Leko. 2017. « Reviewing Research on the Self-Determined Learning Model of Instruction: Mapping the Terrain and Charting a Course to Promote Adoption and Use. » Advances in Neurodevelopmental Disorders 1 : 3-13. DOI: $10.1007 / \mathrm{s} 41252-017-0007-7$

Hutchins, N.S., M.D. Burke, H. Hatton, and L. Bowman-Perrot. 2017. "Social Skills Interventions for Students with Challenging Behavior: Evaluating the Quality of the Evidence Base.” Remedial and Special Education 38(1): 13-27.

Kazdin, A.E. 2011. Single-Case Research Designs. Second Edition. Oxford University Press. Ch.1.

Kinney, J. and T. Kinney. 2003. Attainment's Social Standards at School. Instructor's Guide. Verona, Wisconsin: Attainment Company, Inc.

Kleinert, J.O., E. Harrison, K.R. Mills, B.M. Dueppen, and A.M. Trailor. 2014. "Self-determined Goal Selection and Planning by Students with Disabilities across Grade Bands and Disability Categories." Education and Training in Autism and Developmental Disabilities 49: 464-477. 
Krasny, L., B.J. Williams, S. Provencal, and S. Ozonoff. 2003. "Social Skills Interventions for the Autism Spectrum: Essential Ingredients and a Model Curriculum." Child and Adolescent Psychiatric Clinics 12: 107-122.

Lee, S., M.L. Wehmeyer, and K.A. Shogren. 2015. "Effect of Instruction with the SelfDetermined Learning Model of Instruction on Students with Disabilities: A MetaAnalysis." Education and Training in Autism and Developmental Disabilities 50: 237247.

Reichow, B. and F.R. Volkmar, F.R. 2010. "Social Skills Interventions for Individuals with Autism: Evaluation for Evidence-Based Practices within a Best Evidence Synthesis Framework." Journal of Autism and Developmental Disorders 40: 149-166. DOI: $10.1007 / \mathrm{s} 10803-009-0842-0$

Seo, H.J., M.L. Wehmeyer, S.B. Palmer, J.H. Soukup, K. Williams-Diehm, and K. Shogren. 2012. "Examining Individual and Environmental Factors on Levels of Self-Determination of Students with Disabilities: The Relationship between Self-Determination and Disability Categories, Gender, and Educational Settings.” The Journal of Special Education: Theory and Practice, 13:2, 1-22.

Shogren, K.A., S.B. Palmer, M.L. Wehmeyer, K. Williams-Diehm, and T.D. Little. 2012. "Effect of Intervention With the Self-Determined Learning Model of Instruction on Access and Goal Attainment." Remedial and Special Education 33: 320-330. DOI: $10.1177 / 0741932511410072$

Shogren, K.A., M.L. Wehmeyer, and S.B. Palmer. 2017. “Causal Agency Theory.” In Development of Self-Determination Through the Life-Course, edited by M.L. Wehmeyer, 
K.A. Shogren, T.D. Little and S.J. Lopez. Dordrecht. The Netherlands: Springer Science + Business Media B.V. Ch.5.

van Engeland, H. and J.K. Buitelaar. 2008. Autism Spectrum Disorders. In Rutter's Child and Adolescent Psychiatry, $5^{\text {th }}$ edition, edited by M. Rutter, D. Bishop, D. Pine, S. Scott, J. Stevenson, E. Taylor \& A. Thapar. Oxford: Blackwell Publishing Ltd.

Wehmeyer, M.L., S.B. Palmer, M. Agran, D.E. Mithaug and J.E. Martin. 2000. "Promoting causal agency: The Self-Determined Learning Model of Instruction.” Exceptional Children 66: 439-453.

Wehmeyer, M.L. and K.A. Shogren. 2017. "The Development of Self-Determination During Adolescence." In Development of Self-Determination Through the Life-Course, edited by M.L. Wehmeyer, K.A. Shogren, T.D. Little and S.J. Lopez. Dordrecht. The Netherlands: Springer Science + Business Media B.V. Ch.7.

Wehmeyer, M.L., K.A. Shogren, D. Zager, T.E.C. Smith, and R. Simpson. 2010. "ResearchBased Principles and Practices for Educating Students with Autism: Self-Determination and Social Interactions." Education and Training in Autism and Developmental Disabilities 45(4): 475-486. 
Figure 1: SDLMI - Phase 1: Set a goal

\section{SDLMI - Phase 1: Set a goal}

1. What do I want to learn or improve?

Small-talk with the other girls during lunch.

2. What do I know about it now?

I don't know. I can answer when somebody asks me a question, but I don't know how to start a conversation myself. I don't know what to talk about.

3. What must change for me to learn what I don't know?

I don't know. I need to figure out what I can talk about and how I can start a conversation.

4. What can I do to make this happen?

I don't know. I can find out things to talk about. 
Figure 2: SDLMI - Phase 2: Take action

\section{SDLMI - phase 2: Take action}

1. What can I do to learn what I don't know?

I don't know. I can try and find out what I can talk about. I can practice what I could say.

2. What could keep me from taking action?

If I remain seated in between the boys during lunch.

3. What can I do to remove these barriers?

I could change places and sit together with the other girls.

4. When will I take action?

I can start next week. 
Figure 3: Five-point script for lunch talk

\section{RECIPE LUNCH TALK}

1. SAY NAME OF FRIEND I WANT TO TALK WITH

2. LOOK AT FRIEND

3. ASK A QUESTION

4. LISTEN TO RESPONSE

5. ASK ANOTHER QUESTION OR GIVE A RESPONSE 
Figure 4: SDLMI - Phase 3: Adjusting the goal or plan

Phase 3: Adjusting the goal or plan

1. What actions have I taken?

I've figured out things to talk about, and I've listened to what the others in my class said.

2. What barriers have been removed?

The boys changed places.

3. What has changed about what I don't know?

I don't know. The practicing helped me so I know what to say.

4. Do I know what I want to know?

I think so. 
Figure 5: Progress chart

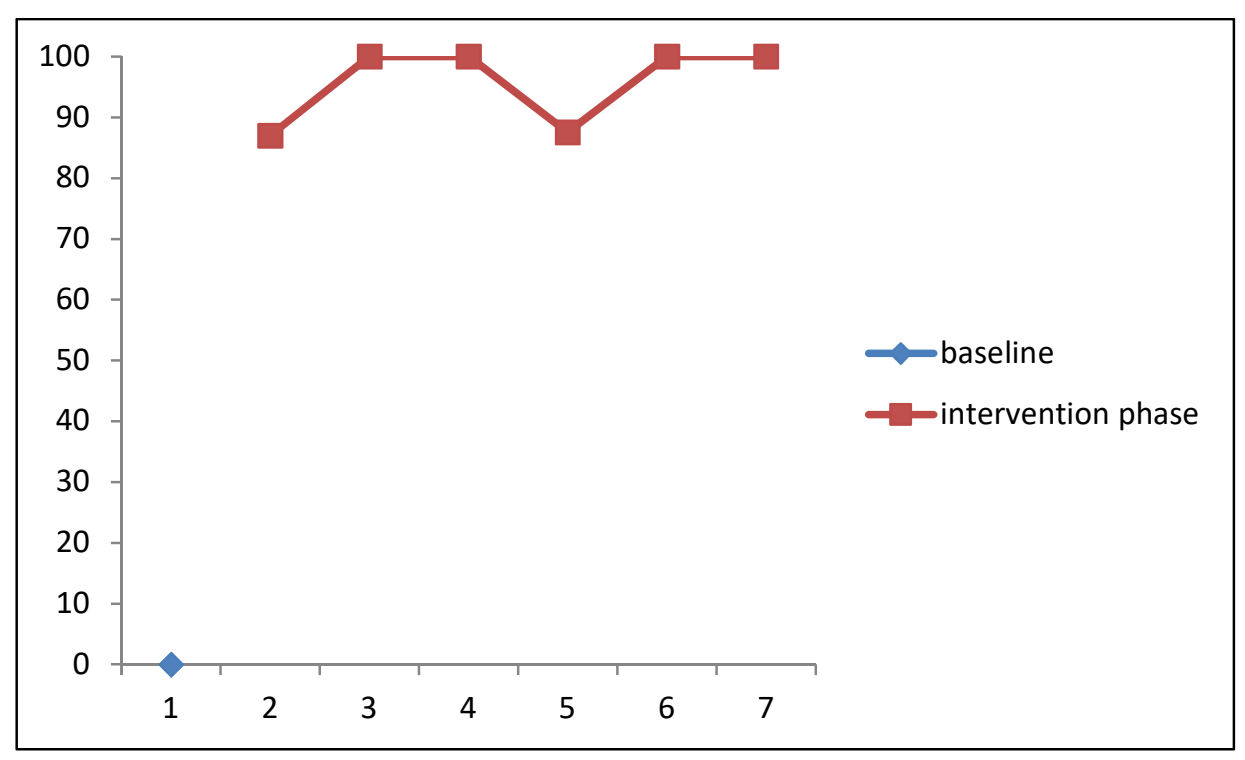

